\title{
Calculating the Macroscopic Dynamics of Gas/Metal/Slag Emulsion during Steelmaking
}

\author{
Stephen SPOONER, ${ }^{1 * *}$ Jason Marc WARNETT, ${ }^{2)}$ Rohit BHAGAT, ${ }^{3)}$ Mark Antony WILLIAMS ${ }^{2)}$ and \\ Seetharaman SRIDHAR ${ }^{1)}$
}

1) International Digital Laboratory, Warwick Manufacturing Group, University of Warwick, Coventry, West Midlands, CV4 7AL UK. 2) International Manufacturing Centre, Warwick Manufacturing Group, University of Warwick, Coventry, West Midlands, CV4 7AL UK.

3) Energy Innovation Centre, Warwick Manufacturing Group, University of Warwick, Coventry, West Midlands, CV4 7AL UK.

(Received on June 14, 2016; accepted on August 9, 2016; J-STAGE Advance published date: November 8, 2016)

\begin{abstract}
The average residence time, metal circulation rates and percentage tap weights of metal suspended in the emulsion of a Basic Oxygen Furnace (BOF) are calculated under defined assumptions. Data has been taken from the IMPHOS (Improved Phosphorus Refining) project in which a 6 tonne BOF was simultaneously sampled at selected depths and at selected times under controlled operating conditions. ${ }^{11}$ A discussion is given on the formation of the model and as to the diversion from previously reported findings from this data. ${ }^{2)}$ Links have been made between the macroscopic parameters calculated and the chemical refining performance seen through the heats. X-ray computer tomography has given information on droplet size and numbers in the emulsion. With the data used to validate the proposed model.
\end{abstract}

KEY WORDS: steelmaking; residence time; gas/slag/metal emulsion; basic oxygen furnace.

\section{Introduction}

With rising ore prices and the ever growing competition from mass produced steel, a transformation to specialist steels and variable production processes are being investigated by many institutions throughout the world. The processing of lower grade ores is a topic of particular interest, as reduction of raw material cost is a key way to combat the economic sway of the steel industry.

Typically lower-cost ores exhibit higher phosphorus (P) content, ${ }^{3)}$ an element undesirable in the final product as significant segregation results in phosphorus enriched cores, reducing ductility and increasing the brittleness of the final steel product. ${ }^{4,5}$ Therefore, low phosphorus levels are essential for the manufacturing of thin sheet, deep drawn and automobile exterior parts among many others.

Currently phosphorus levels are controlled through operation of the Basic Oxygen Furnace (BOF); however this is a secondary function of the converter, whose main job is decarburization (the reaction pathways shown in Eqs. (1) and (2)). As a result processing parameters have to be balanced and inhibiting factors such as oxygen removal and high temperatures occur which reduce the phosphorus refining performance of the BOF.

$$
(\mathrm{FeO})+[\mathrm{C}] \rightarrow \mathrm{CO}_{(\mathrm{g})}+[\mathrm{Fe}]
$$

\footnotetext{
* Corresponding author: E-mail: S.R.A.Spooner@warwick.ac.uk
} DOI: http://dx.doi.org/10.2355/isijinternational.ISIJINT-2016-361

$$
\mathrm{CO}_{2(g)}+[\mathrm{C}] \rightarrow 2 \mathrm{CO}_{(g)}
$$

The notation for the reaction equations in this paper section is such that:

[ ] represents content in the metal,

( ) represents content in the slag,

T.Fe represents total $\mathrm{Fe}$ in the slag

Oxygen partial pressures within the basic oxygen furnace drive the stability of phosphorus in the slag as phosphate ions, $\left.\left(\mathrm{PO}_{4}{ }^{3-}\right){ }^{6}\right)$ The ionic reaction is given in Eq. (3):

$$
[\mathrm{P}]+2.5(\mathrm{FeO})+1.5\left(\mathrm{O}^{2-}\right)=\left(\mathrm{PO}_{4}^{3-}\right)+2.5[\mathrm{Fe}] .
$$

The slag's capability to remove phosphorus is described by the phosphorus partition ratio $\left(L_{p}\right)$, this is used synonymously by researchers with the apparent phosphorus partition $\left(k_{p}\right)$ defined in Eqs. (4) and (5):

$$
\begin{gathered}
L_{p}=\frac{(\% P)}{[\% P]} \\
k_{p}=\frac{L_{p}}{(T . F e)^{\frac{5}{2}}} .
\end{gathered}
$$

The logarithmic of apparent phosphorus partition $\left(k_{p}\right)$ can be expressed as a function of temperature and slag composition, after regression analysis of controlled equilibrium experimental data. See Eq. (6): ${ }^{7,8)}$ 


$$
\begin{aligned}
\log \left(\frac{L_{p}}{F e_{t}^{2.5}}\right)= & 0.06\left\{(\% \mathrm{CaO})+0.37(\% \mathrm{MgO})+4.65\left(\% \mathrm{P}_{2} \mathrm{O}_{5}\right)\right. \\
& \left.-0.05\left(\% \mathrm{Al}_{2} \mathrm{O}_{3}\right)-0.2\left(\% \mathrm{SiO}_{2}\right)\right\}+\frac{11570}{T}-10.52
\end{aligned}
$$

Given the low concentrations of phosphorus and oxygen in experimental melts, the phosphorus activity coefficient is known to be close to unity when the Henrian standard state is used. As such Eq. (3) has a bias to the right, giving favourable partition of phosphorus into the slag when the pathway is enabled. This is achieved both chemically through lime availability, and higher iron (II) oxide (FeO) content in the slag; as well as thermally through operation at favourable lower temperatures (still within the liquid range). Phosphorus partition in the BOF, is not at equilibrium for the conditions; there is a higher level of phosphorus left in the metal than potential partition allows for. As such the kinetics of the phosphorus transfer pathway must be considered. ${ }^{9)}$

The dephosphorization reaction consists of a series of potentially kinetic limiting steps:

1. Transfer of phosphorus from bulk steel to slag/steel interface

2. Transfer of oxygen ions from bulk slag to slag/steel interface

3. Chemical reaction at slag/steel interface

4. Transfer of oxygen from slag/steel interface to bulk steel

5. Transfer of phosphate ions from slag/steel interface to bulk slag

Due to the high temperatures of the process, it is typically assumed the chemical reaction at the interface can be ruled out as rate limiting due to the speed at which it takes place. As a result the rate is believed to be predominantly controlled by the mass transfer of ions in either or both bulk metal and slag. ${ }^{9-11)}$ The term "bulk metal" in this case refers to a region where the material is compositionally constant in space and could be in the metal bath or inside a metal droplet. This leads to a rate of dephosphorization dependent upon metal packet size, and the time period required for that metal to refine. Therefore the transient interfacial area is a macroscopic kinetically restricting factor for phosphorus refining. The quiescent interface of the bulk bath is a small portion of the overall metal/slag interface, as the emulsion phase of the BOF contains a dispersion of metal packets/ droplets. Previous studies have investigated the range of what sizes these droplets are. ${ }^{112-19)}$ However coupled with this information it is important to know the percentage of metal accounted for in the emulsion (\% tap weight), the metal circulation rate within the emulsion (as this effects localised diffusion gradients), and how long the metal remains in the emulsion (residence time).

Residence times have been both modelled and calculated from blow sampling in several previous studies. The residence time is defined as the period of time which has lapsed between a "packet of metal" leaving the surface and re-entering the bulk bath. Table 1 shows a summary of the previous reported residence times, the author and the method of calculating/modelling the process.

The IMPHOS project was a European funded project
Table 1. Collation of previously reported residence times, with

\begin{tabular}{|c|c|c|}
\hline Author & Method of Deduction & $\begin{array}{l}\text { Residence } \\
\text { Time (s) }\end{array}$ \\
\hline Price $^{20)}$ & $\begin{array}{l}\text { Gold isotope tracking, plant measure- } \\
\text { ment }\end{array}$ & $120 \pm 30$ \\
\hline Kozakevitch $^{21)}$ & $\begin{array}{l}\text { Plant measurement of carbon and } \\
\text { phosphorus level predictions in metal }\end{array}$ & $60-120$ \\
\hline Brooks et al. ${ }^{22)}$ & $\begin{array}{l}\text { Revised prediction to droplet trajec- } \\
\text { tory model, with bloated droplet } \\
\text { effects. On a defined } 15 \% \mathrm{FeO} \text { and } \\
<85 \% \text { gas fraction }\end{array}$ & $20-80$ \\
\hline Dogan et al..$^{23,24)}$ & $\begin{array}{l}\text { Similar to Brooks et al., but } 14-30 \% \\
\text { FeO content screened and a fixed gas } \\
\text { fraction of } 80 \%\end{array}$ & $0.4-45$ \\
\hline Qing $^{25)}$ & $\begin{array}{l}\text { 3-D two phase (mercury/glycerine) } \\
\text { model }\end{array}$ & $1-40$ \\
\hline Schoop et al. ${ }^{26)}$ & $\begin{array}{l}\text { Calculated from a kinetic model and } \\
\text { chemical analysis of indirect plant } \\
\text { samples }\end{array}$ & $\sim 60$ \\
\hline
\end{tabular}
the experimental/modelling technique used.

to investigate the process of phosphorus refinement in the Basic Oxygen Steelmaking (BOS) converter. A 6 tonne converter was sampled at systematic time intervals, simultaneously at selected levels throughout several heats ${ }^{1}$. This sampling procedure enabled metal collection and compositional analysis of the metal in the emulsion in addition to that in the bulk bath during an un-interrupted blow. Using data from IMPHOS trials macroscopic dynamic factors such as the mass of metal in the emulsion, the average residence time (ART) of this metal, and the dynamic emulsion flow speeds can be calculated. The accurate quantification of these parameters is vital to fully understanding and optimising BOF refining. This paper explores calculating macroscopic dynamics based upon carbon mass balancing from realistically attainable plant data, whilst neglecting previous widely accepted significant factors to still offer an accurate result.

\section{Materials and Methods}

\subsection{Heat Characteristics}

This paper interrogates 14 of the 25 heats conducted during the IMPHOS trials; these heats were selected due to consistently reliable data sets, and the inclusion of varying factors such as sampling time and hot metal silicon content. The heats included are: S1828-S1837, S1840, S1843; S1845 $\&$ S1846, the nomenclature for heat naming has been kept the same as the original IMPHOS report for ease of reference. ${ }^{1)}$ The IMPHOS report is publically available and can be found on the website for the European Commission.

The nominal composition for hot metal used in the trial is given in Table $\mathbf{2}$ and is near "normal" to hot metal outputs from the blast furnace in industrial practice to increase relevance to application:

Further breakdown of individual heat conditions, and parameters such as ' $V$ ' ratio (mass\% $\mathrm{CaO} / \mathrm{mass} \% \mathrm{SiO}_{2}$ ), lime addition, lance height profiles and tapping temperatures can be found in the European Commission report. ${ }^{1)}$ The authors recommend the data in the report is considered when evaluating the findings in the present paper. 
Table 2. Nominal start composition of hot metal used in IMPHOS trials.

\begin{tabular}{cccccc}
\hline C mass\% & Si mass\% & Mn mass\% & P mass $\%$ & S mass $\%$ & Temp ${ }^{\circ} \mathrm{C}$ \\
\hline 4.75 & 0.45 or 0.6 & 0.45 & 0.085 & 0.03 & 1375
\end{tabular}

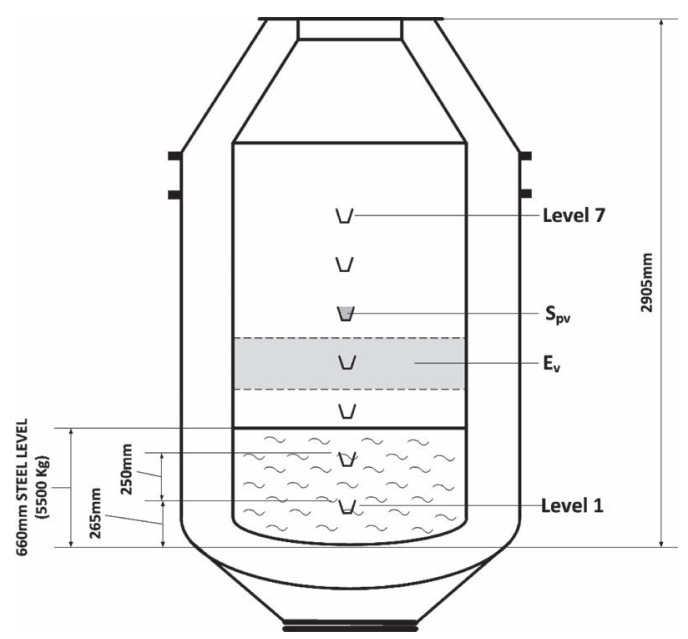

Fig. 1. Schematic of MEFOS 6 tonne converter with sample levels, dimensions and $\mathrm{Spv} / \mathrm{Ev}$ defined.

IMPHOS trials were carried out at Swetea MEFOS, Sweden, with use of the 6 tonne pilot plant BOS converter. The converter has a lining of Magnesia-Carbon (fired and fused) bricks, and is fitted with a single bath agitation tuyere blowing nitrogen at a rate of $0.5 \mathrm{Nm}^{3} \mathrm{~min}^{-1}$ and a water-cooled oxygen lance with a single De-Laval nozzle (a convergent divergent nozzle; a pinched geometry to make an asymmetric hourglass shape) blowing oxygen at $17 \mathrm{Nm}^{3}$ $\min ^{-1}$. A schematic of the converter can be seen in Fig. 1 containing dimensions, sampling pot locations and labelling of the terms used later in calculations.

Sampling of the converter was carried out via robotic delivery of specially designed sample lances at 2 minute intervals throughout the blow. The lances consist of an inner and outer structure of three mild steel bars, the inner being joined to the sides of inline sample pots, the outer joined to the sides of disc sample pot lids. The lance is lowered into the converter through an opening in the top (with a slight offset from the oxygen lance), with the lids in the closed position. Once lowered into position, the outer three bars are retracted lifting the lids in-situ, allowing the sample pots to fill. The lids were then closed after 3 seconds for all heats in this study, apart from S1844, S1845 and S1846 where the lids closed after 3.5, 4 and 5 seconds respectively. The lances are then retracted from the converter, the lance carousel rotates and the next lance is lowered after 2 minutes.

A small flake of each sample was extracted (for SEM analysis) after the full sample was weighed. Each sample was then passed three times through a small hammer mill. The material was then magnetically separated by hand-held magnet.

The now magnetic and non-magnetic fractions were weighed separately, and chemically analysed via spark OES. The original IMPHOS report used this to separate the heats into 5 characteristic phosphorus refining profiles. A full collation of IMPHOS sample chemical analysis can be seen in the report.

\subsection{Model of BOS Converter for Calculating Macro- scopic Dynamics}

\subsubsection{Initial Analytical Input}

The method of calculation used in this paper has a significantly different assumption from that in the previously assumed that sampling was linearly dependant on sample pot opening times, it has now been assumed that the sampling of the converter was instantaneous upon opening of the submerged sample pots, and the content of the pot does not change with time.

The reason for this assumption is that upon inspection of the amount of material collected in sample pots, as a function of sample pot opening time, longer opening time's lay within the spread of data produced by the normal three second sampling time for this experiment. If sampling was to depend upon the pot opening time, it would be expected that a trend would exist where the average metal collected per pot per heat would increase with sample pot opening time.

Along with this change in sampling interpretation, a new method of modelling the macroscopic dynamics has been proposed which relies heavily on quantified off-gas analysis. Off-gas analysis is notorious for being inaccurate for full converter analysis. To minimise potential error a mass balance has been carried out between the mass of carbon lost from between input and output hot metal, and that detected in the off-gas.

From the carbon mass balancing a discrepancy of up to around $13 \%$ can be seen, yet in most cases reasonable agreement is seen. To combat this discrepancy, off-gas carbon detection is given a correction variable which uniformly distributes the discrepancy across a heat's blow time.

\subsubsection{Method of Macroscopic Dynamics Calculation}

The model created in this study uses output analysis from IMPHOS trials, such as metal masses, chemical compositions and converter parameters. The main process is an iterative carbon mass balancing between elemental analysis of emulsion zone metal, and that of the bulk bath metal. Carbon mass balancing is used due to the off gas detection offering a higher time resolution sampling in refined material, as opposed to using phosphorus or silicon removal which would only be correlated to the less frequent 2 minute slag sampling. Also decarburization continues to a measureable point throughout the entire blow, where as other impurities are heavily refined earlier, and change little towards the end. Firstly the overall mass of metal in the emulsion zone is calculated through ratio scale up between sample volume and converter volume. The carbon mass balancing of this metal with the timeline of bulk bath composition in the same mass of metal is then used to calculate the ART. Finally a relationship between mass of metal collection and its period of residence is used to calculate metal circulation rate.

Equations (7)-(11) show the necessary steps for calculating the mass of metal in the emulsion, the ART of metal in the emulsion and the metal circulation rate within the emulsion.

Key assumptions beyond those previously stated are:

- The emulsion phase is solely responsible for decarburization. In this study the emulsion phase is defined as levels $4-7$ in the IMPHOS converter. Although it is 
known that there are contributions from the bulk bath, and accelerated rates from the hot zone (the area of oxygen jet impact on the metal bath surface), this was deemed a reasonable working assumption due to the known high rates of carbon removal in the emulsion type phase, a check of the validity of this assumption is offered after the discussion. As such, levels 1-3 are considered bulk bath/interface samples and above level 7 the density of slag is assumed to be such that refining potential would be greatly reduced (a foam).

- The population (mass) of metal in the emulsion was consistent and remained constant throughout the time period covered by the calculated ART unless the calculated ART spanned two sampling points, upon which a regression of change was factored into the calculation. This assumption was necessary in order to perform the calculation and should be evaluated for each individual point as to its reliability. An indication as to its reliability may be to assess the change in metal circulation rate over the relevant time period.

- Sampling was a fair representation of environment throughout the full horizontal plane of the converter. This assumption is not strictly accurate in the vicinity of the main lance and the wall of the converter, but it is adopted because of simplicity. Thus if a cylindrical geometry is considered, it is assumed the changes are only in the z-direction and thus rendering the problem 1D. This was considered to be a fair estimation when assuming constant population as material travelling in both directions through a section should be near equal. Measured input data to the model includes:

$\mathrm{M}_{\mathrm{o}}=$ The mass of metal collected in a single sample pot,

$\mathrm{S}_{\mathrm{pv}}=$ The volume of a single sample pot,

$E_{v}=$ The volume of a defined section of the emulsion zone (depicted in Fig. 1),

$\mathrm{C}_{(\mathrm{e})(\mathrm{t}) \text { mass } \%}=$ The average measured carbon mass percent of the metal from a sample pot in the emulsion zone,

$\mathrm{C}_{(\mathrm{e})(\mathrm{t})}=$ The total mass of carbon in the metal fraction of the emulsion zone at a point in time,

$\mathrm{C}_{(\mathrm{bb})(\mathrm{t}) \text { mass } \%}=$ The average measured carbon mass percent of a sample from the bulk bath (layer 1 in the sample lance), $\mathrm{C}_{(\mathrm{bb})(\mathrm{t})}=$ The actual mass of carbon in the equivalent mass of metal collected in the emulsion at the interrogated time, $\mathrm{C}_{(\mathrm{o})}=$ Mass of carbon detected in the off-gas analysis in 1 second.

Firstly the mass of metal in the emulsion at a point in time is calculated $\left(M_{(e)(t)}\right)$ using a scaling factor dependant on effective emulsion zone and sample pot volume:

$$
M_{(e)(t)}=\sum M_{o}\left(\frac{E_{v}}{S_{p v}}\right)
$$

To carry out this calculation, first the emulsion volume must be deduced, this is achieved by interrogating the slag height profiles of the heats, calculated by inspection of the slag line on a sample lance. Also, in order to get a full representation, missing sample data has to be predicted, for instance if data was available for levels 4 and 6 , but not 5 , since we know 5 must have been occupied. This was done by fitting of a regression given by a full data set within IMPHOS trials with similar known results. The appropriate regression is taken from a heat with similar characteristics (sample sizes, and known distribution) and from the same time point as the sample set with missing data. There is strong consistency in these profiles, the match should give a realistic result.

Next the mass of carbon in the overall emulsion metal at a point in time must be calculated $\left(C_{(e)(t)}\right)$ with use of a measure carbon mass percent of metal, and scaled metal content of the emulsion:

$$
C_{(e)(t)}=\sum\left(\frac{M_{o}\left(\frac{E_{v}}{S_{p v}}\right)}{100}\right) C_{(e)(t) m a s s \%}
$$

The mass of carbon in the bulk bath is now calculated as a function of time for the same mass of metal as was found in the emulsion at time $t$. This is done by using the measure carbon mass $\%$ of bulk bath metal throughout the blow and the scaled mass of metal in the entire emulsion $\left(C_{(b b)}\right)$ :

$$
C_{b b(t)}=\left(\frac{M_{(e)(t)}}{100}\right) C_{(b b)(t) m a s s \%}
$$

It is now possible to add off-gas carbon detection values to the emulsion metal carbon weight, in 1 second steps back in time from the sampling point. This time-step carbon addition will intersect the local linear regression of analysed bulk bath carbon content for the corresponding heat, as such:

$$
C_{(b b)\left(t-t_{r}\right)}=C_{(e)(t)}+\sum_{i=o}^{n} C_{(o) i}
$$

Where $C_{(o)}$ is the mass of carbon, detected in the off gas in the nth second, prior to sampling. The ART of all metal in the emulsion at time $t$ in seconds is $\left(t_{r}\right)$ :

$$
t_{r}=n
$$

This includes metal recently ejected from the bulk bath, the metal soon to re-enter and all points in-between. Given the units of $M_{(e)(t)}(\mathrm{kg})$, and $t_{r}(\mathrm{~s})$, it is now possible to calculate the metal circulation rate $(M C R)$ within the emulsion as defined previously by Millman et al.:2)

$$
M C R=\frac{M_{(e)(t)}}{t_{r}}
$$

\subsection{X-ray Computed Tomography}

Flakes of emulsion in solidified form from four different samples were scanned using X-ray Computed Tomography (XCT) for 3D observation of the steel in slag. Furthermore this could be segmented to determine the position, size, volume and surface area of each droplet contained within the slag. From the relatively uniform distribution of pores and metal droplets through the samples it is expected the samples solidified rapidly (if a slow solidification took place it would be expected the difference phases in a sample would have separated by density to a large extent, this behaviour was not seen), as such the ex-situ investigation of the droplet sizes and distribution is a good representation of the original environment.

The sample is placed on a rotating turntable between the 
source and detector. The scanner used in this study was the Nikon XT 225/320 with the parameters listed in Table 3. As $\mathrm{X}$-rays traverse the sample they are either attenuated or pass through resulting in a grey-scale radiograph on the screen. Numerous images are taken through 360 degrees which are then reconstructed into a $3 \mathrm{D}$ volume through the process of filtered back projection. The volume consists of a number of $3 \mathrm{D}$ pixels called voxels with an associated grey value between 0 and 65535 , proportional to the attenuation of the material. Validation of the instrument's accuracy has been reported by Kumar et al. ${ }^{20)}$

\section{Results}

The $\%$ tap weight (the amount of metal in the emulsion as a percentage of final tap weight), ART and metal circulation rate within the emulsion at a point in time have been calculated for 14 heats from a 6 tonne pilot plant basic oxygen furnace. The highest average $\% T w$ in the emulsion being is $31.07 \%$, and the highest average ART being $69 \mathrm{~s}$; both of which occur in heat S1835. The highest average metal circulation rate is that of $\mathrm{S} 1837$ being $305.41 \mathrm{~kg} \mathrm{~s}^{-1}$. Much larger variation is seen in the MCR of blows than that of $t_{r}$ and $\% T w$. Table 4 shows the overall averages of all three parameters, and their respective standard deviation to give an idea of cross heat differences.

For the purposes of this paper the selected IMPHOS heats have been split into three groups based on their computed ART profiles, these groupings are qualitative and a devise to aid presentation and discussion of results in the paper, the authors are not stating it is possible to categorise all BOF profiles coherently into one of the three groups presented here. The three groups are: "Mid blow inflection" where the profiles show a raised and sustained relatively high ART through early blow, followed by a drastic decrease around the middle period of the blow, with the ART then staying low for the remainder of the blow; "High start then fluctuation" when profiles show a large rise in ART up to 6 minutes into the blow, this peak then rapidly decreases, followed by smaller fluctuations up and down in ART for the remainder of the blow; "Residual Heats" show profiles

Table 3. XCT scanning parameters used for the interrogation of solid emulsion shards removed from the sampling pots.

\begin{tabular}{cc}
\hline Voltage $(\mathrm{kV})$ & 180 \\
Current (micro A) & 24 \\
Exposure (s) & 2.8 \\
Filter (Cu, mm) & 0.5 \\
\# Projections & 3200 \\
Voxel size (microns) & 41 \\
\hline
\end{tabular}

Table 4. Overall average and SD of $\% \mathrm{Tw}, \mathrm{t}_{\mathrm{r}}$, and $\mathrm{MCR}$ for all blows.

\begin{tabular}{cccc}
\hline & $\begin{array}{c}\text { Overall } \\
\text { Average \% Tw }\end{array}$ & $\begin{array}{c}\text { Overall } \\
\text { Average } \mathrm{t}_{\mathrm{r}} \mathrm{s}\end{array}$ & $\begin{array}{c}\text { Overall Average } \\
\text { MCR kg s }^{-1}\end{array}$ \\
\hline $\begin{array}{c}\text { Mean Average } \\
\text { Standard } \\
\text { Deviation }\end{array}$ & 21.30 & 39 & 87.48 \\
\hline
\end{tabular}

unfitting to the previous two groupings, these can be from an increased sustained high ART, to peaking mid blow, or even a very low ART profile throughout the entire blow. There is no correlation between these groupings and the operating conditions, input parameters or measured output data from the experimental trial. Similarly scales of the different grouping graphs that follow are different in the y-direction due to significantly varied numerical results and the need to keep profile differences clear within a single sub-set.

\subsection{Amount of Metal in the Emulsion}

The amount of metal suspended in the emulsion is given as a percentage of the final tap weight, rather than the input hot metal mass. This is due to $\mathrm{FeO}$ production and sublimation of Fe material during a blow, resulting in a reduced possible mass as the process continues. This is given as a function of blow time in Fig. 2.

\subsection{Average Residence Time in the Emulsion}

It should be noted these calculations are ART for packets of metal in the emulsion. When the process is considered

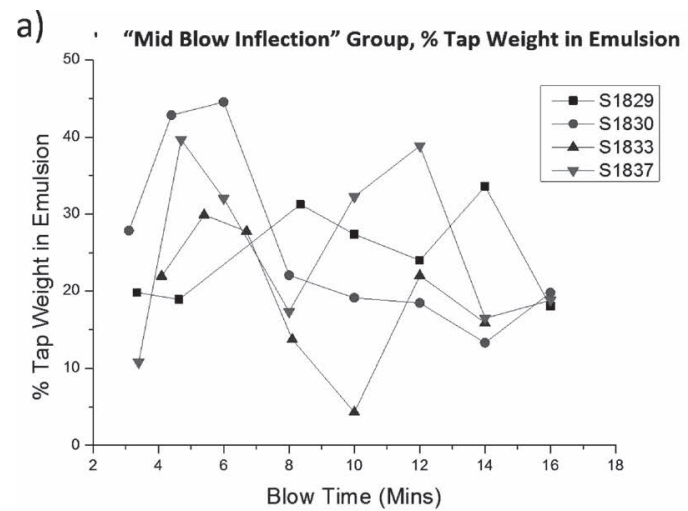

b) “High Start then Fluctuation" Group, \% Tap Weight in Emulsion

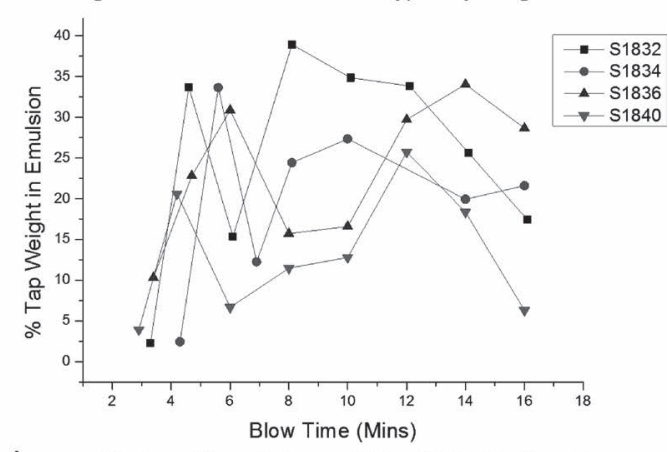

C) "Residual Heats" Group, \% Tap Weight in Emulsion

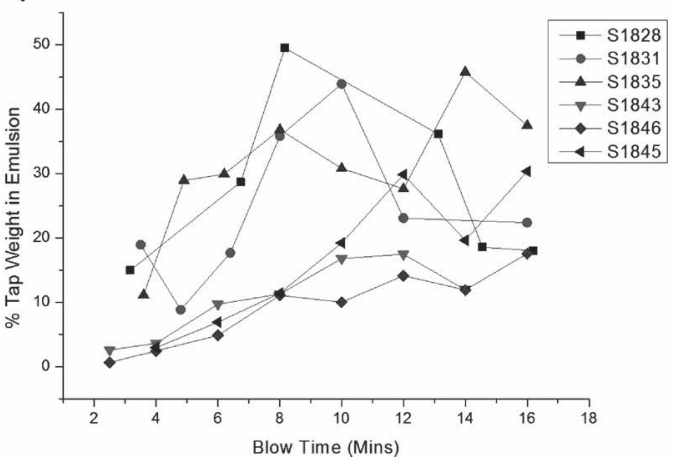

Fig. 2. The amount of metal in the emulsion as a percentage of final tap weight. a) "Mid blow inflection" group, b) "High start then fluctuation" group, c) "Residual heats" group. 
it is correct to propose that the spread of residence times is variable from the calculated average through to a near zero second residence time, for instance some material will reenter the bulk bath almost as soon as it leaves. Therefore residence time of individual packets of metal will be greater than the average calculated. This should be taken into account when interpreting the given ART, the defining of the greatest divergence from the calculated ART (min and $\max$ ) is however beyond the scope of this work. The ART as a function of blow time is given in Fig. 3.

\subsection{Metal Circulation Rate in the Emulsion}

The speed of movement effect of end of blow results on the scale of graphical display. With the exceedingly high rates seen in the last 2 minutes of the blow within the converter emulsion it is important to consider; the first thing to note from the results of metal circulation rate is the graph gives the illusion of a sustained rate up until this point, seen in Fig. 4. Secondly, the metal circulation rates reported are an average of the overall emulsion, much as the reported
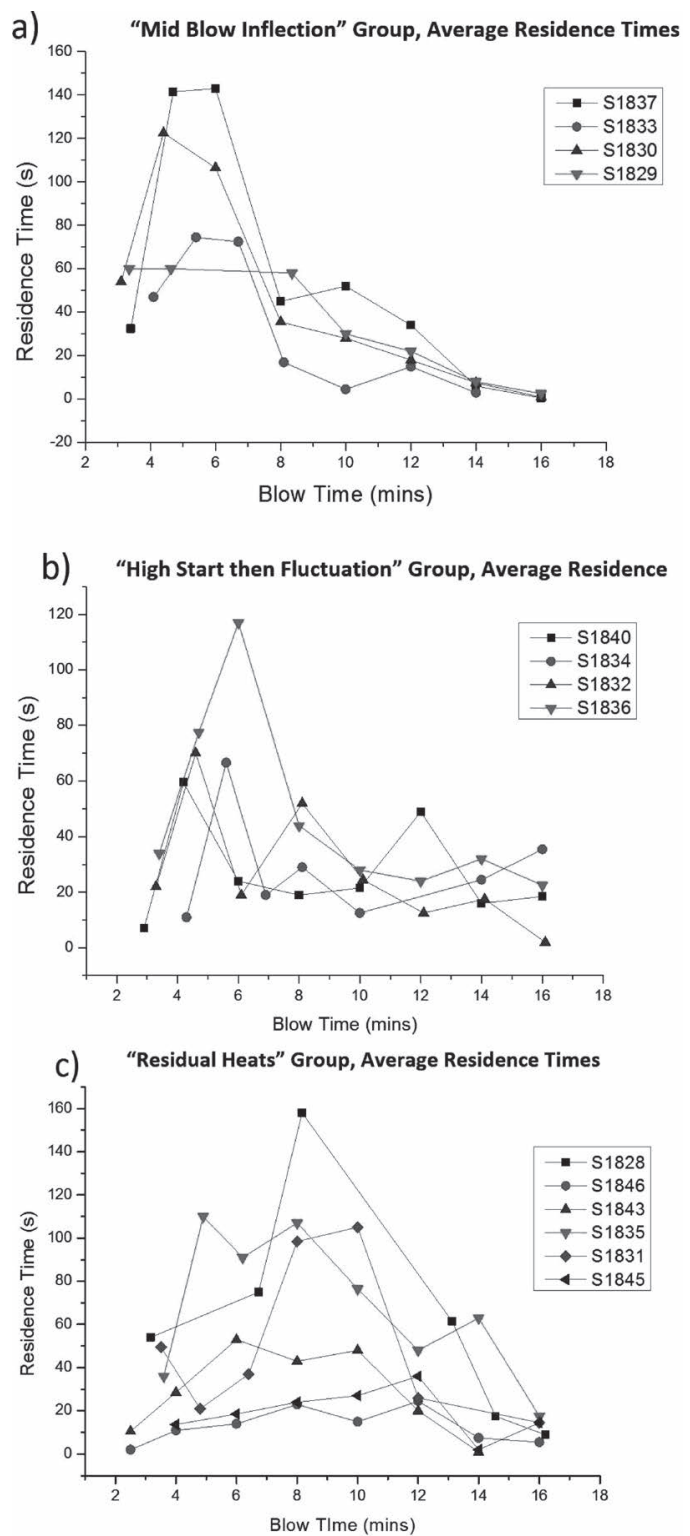

Fig. 3. The average residence time as a function of blow time. a) "Mid blow inflection" group, b) "High start then fluctuation" group, c) "Residual heats" group. residence times; individual packets of metal may be moving much fast or slower than the times calculated here.

\subsection{XCT Results of Slag/Gas/Metal Emulsion Samples}

An example 2D orthoslice of the resulting volume can be seen in Fig. 5 where the bright white areas are metal droplets, the light grey areas slag material and black areas porosity. As can be seen in the image the attenuation, and hence grey value, of the slag is much lower than the steel, allowing for simple segmentation using the Otsu method. ${ }^{21)}$ The 3D output of the segmentation can be observed in Fig. 6 where the metal can be seen as light grey areas in the emulsion shards, and the slag (darker grey) has been made semitransparent to allow viewing through the sample. Using the analysis software Avizo 8.1 (FEI, USA) individual steel pellets were then analysed for each individual flake providing the $\mathrm{min} / \mathrm{max}$ diameter, volume and surface area. Table 5 gives an overall example of the results from XCT interrogation of the shard emulsion samples.

With the use of XCT, the authors are able to remove any droplets which may have been dissected at the surface of

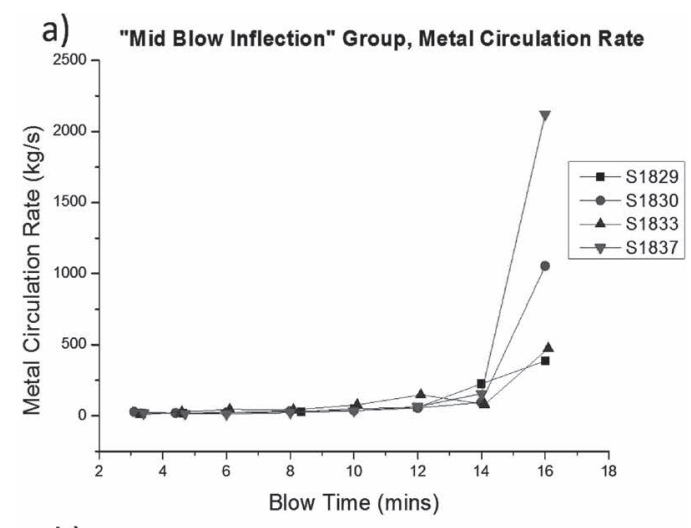

b) "High Start then Fluctuation" Group, Metal Circulation Rates
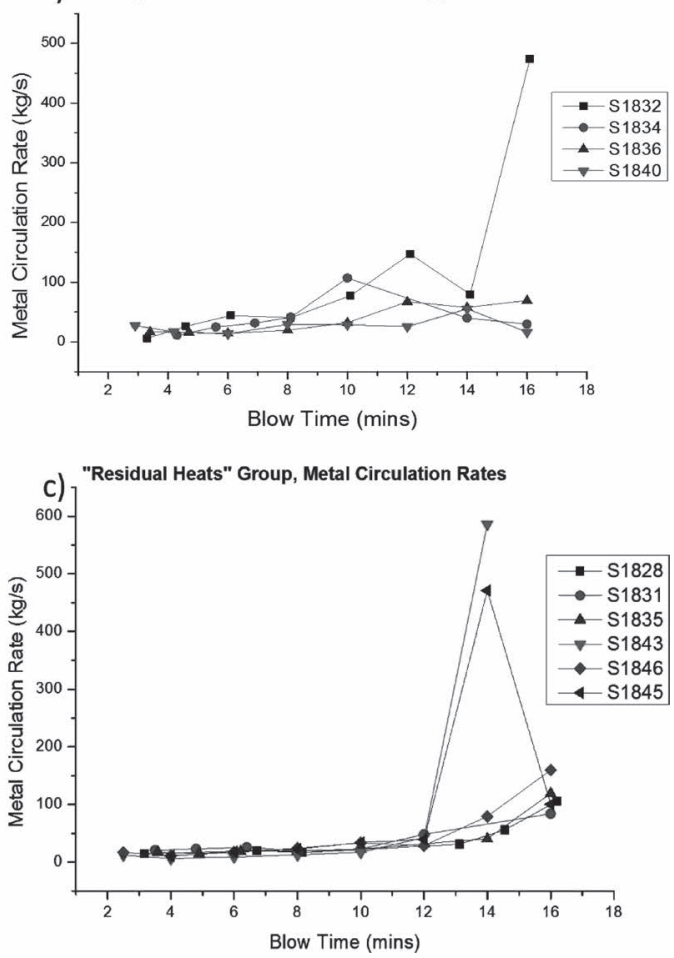

Fig. 4. Metal circulation rates in the emulsion as a function of blow time. a) "Mid blow inflection" group, b) "High start then fluctuation" group, c) "Residual heats" group. 


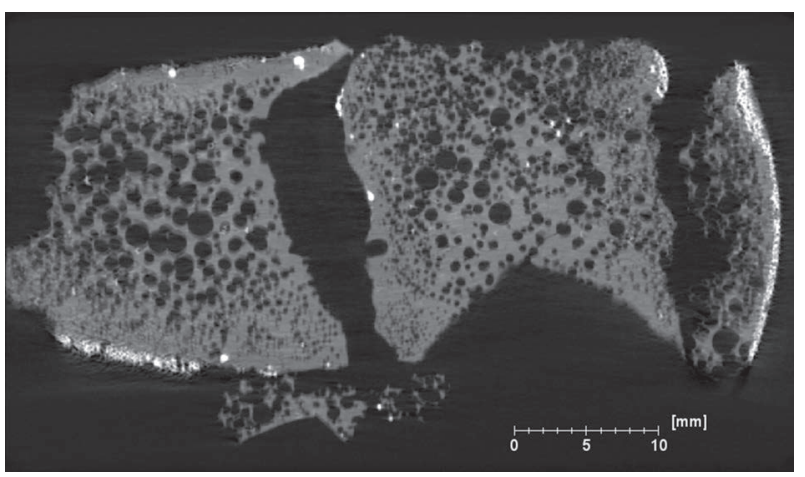

Fig. 5. 2D orthoslice of the $3 \mathrm{D}$ volume. There is a clear contrast between the steel (whitest), the slag (grey) and porosity within the sample (black).

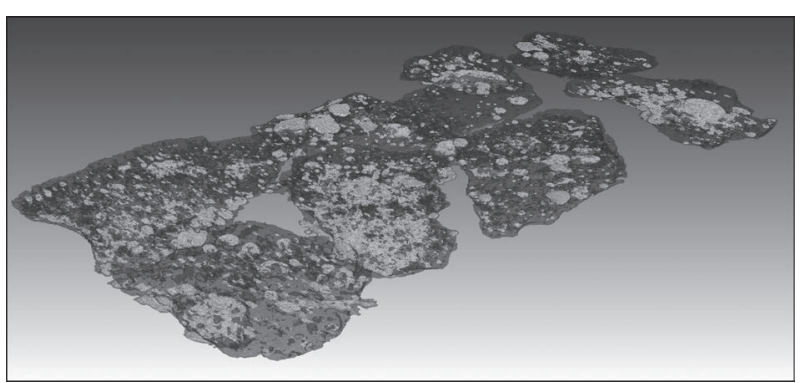

Fig. 6. 3D segmentation with semi-transparent slag phase in order to see the dispersion of metal droplets (light grey).

Table 5. Initial rudimental results from XCT scanning of shard emulsion samples. The number of discrete metal packages detected and their average diameter.

\begin{tabular}{lcc}
\hline Sample ID & No Droplets & Mean Droplet Diameter $\mu \mathrm{m}$ \\
\hline S1840_4_4 & 1062 & 375 \\
S1840_4_5 & 841 & 292 \\
S1840_4_6 & 469 & 307 \\
S1840_4_7 & 133 & 322 \\
Combined & 2505 & 324 \\
\hline
\end{tabular}

the sample from the output results. This removes the unreliability of unknown droplet sectioning as has previously been the case in similar studies, as well as the linking of what would appear to be separate droplets on a sample surface but are in fact connected in the subsurface of the material. Along with the greater certainty of droplet size reporting's, XCT allows for a greater sample set to be analysed as the full dispersion of droplets through the sample can be investigated, not just those at the polished surface as has been the previous method via optical microscopy. ${ }^{1)}$ Visual investigation of the reconstructed images showed that many metallic surface sections showed the sub-surface linking previously suggested. Coupled with the detection of larger droplets than sizes previously reported, this gives the explanation as to why the average droplet size reported in this study is so much larger than the $28-51$ micron range and modal 20 micron average previously reported for these samples. ${ }^{1)}$

\section{Discussion}

\subsection{Residence Times}

The highest calculated ART is that of heat S1828, 8.2
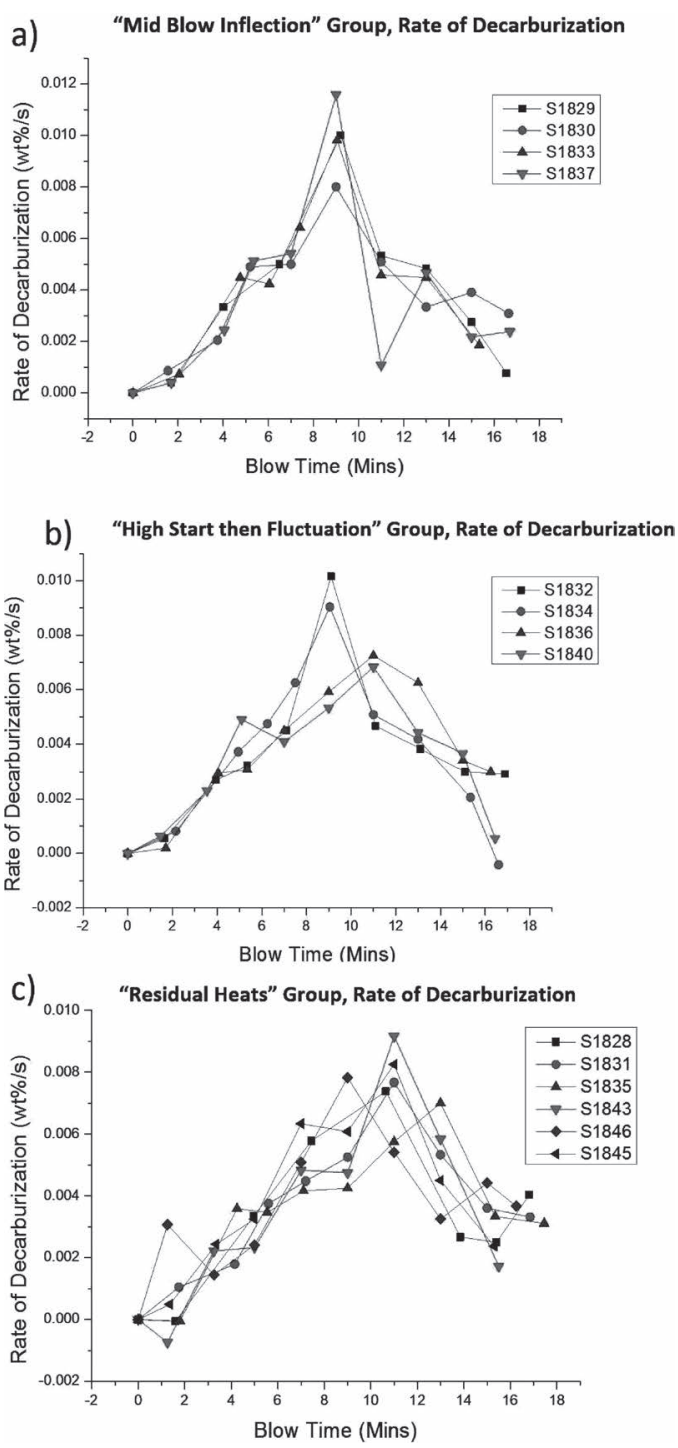

Fig. 7. Rates of decarburization from IMPHOS analysis. a) "Mid blow inflection" group, b) "High start then fluctuation" group, c) "Residual heats" group.

minutes into the blow with a value of $158 \mathrm{~s}$. This value is of the same magnitude of most previous work with the closest being that of Price and the isotopic labelling technique. ${ }^{19)}$ This high value is an outlier and if the overall average of $39 \mathrm{~s}$ is taken, the author believes the results to be closest to that of Brooks et al. ${ }^{22)}$ of $20-80 \mathrm{~s}$, giving a mid-point closest to the average value here, as well as a realistic range.

It should be noted that the highest ART calculated do not necessarily correspond directly to times of the highest decarburization rate, in fact there is a strong correlation of highest ART peaking just prior to the largest decarburization rates as seen in Fig. 7 (the decarburization rate has been calculated from the measured carbon content of sampled bulk bath material through the respective blow; it is noted that the decarburization rate profiles show strong similarity within the groups that have been defined by residence time performance, indicating a significant link between the two). This makes sense as the decarburization rates are calculated from the bulk bath measurements. As the refining takes place in the high residence time droplets, a time-lapse close to the previously measured residence time would be required in order to notice this effect. As an example S1837 has a peak in ART at 6 minutes followed by a peak in decarburization 
as 8 minutes. As ART is over 120 seconds at 6 minutes, it is understandable that the higher decarburization performance is not expressed until later into the blow when these longerexposed packets of metal have had time to recombine with the bulk bath. Thus it is strongly suggested high residence times lead to higher decarburization rates. This is in agreement with the work by Brooks, ${ }^{22)}$ as the initial trajectory modelling carried out was given a correction of transient droplet density due to decarburization reported by Molloseau and Fruehan, ${ }^{23)}$ resulting in the previously reported values by Brooks.

There is a visible correlation between points of higher ART and higher dephosphorization rates, as shown in Fig. 8 (the dephosphorization rate has been calculated from the measured phosphorus content of sample bulk bath material through the respective blow; it is noted that dephosphorization rate profiles show less agreement with the residence time groupings than decarburization, however there are still more common profile trends within each group). This correlation is seen in the early blow with factors such as unfavourable temperature rise, removal of $\mathrm{FeO}$ from the slag by decarburization and a reduction in phosphorus partition gradient becoming increasingly unfavourable through the blow.

If the accepted strong link of high decarburization rates inhibiting dephosphorization are considered and taken into account when observing the given profiles, it is arguably seen that dephosphorization rates are slightly higher at periods of higher ART. This should be understood to be due to a larger effective interfacial area between slag and metal, which aids in dephosphorization due to the nature of phosphorus refinement through interfacial exchange. Not only is there a potential for greater numbers of droplets in the emulsion phase at higher ART (assuming constant droplet formation), the individual droplets are in contact with the slag for a longer period of time, allowing for reactions between the two phases to occur for longer and impurities to gain a closer phase balance to thermodynamic equilibrium.

\section{2. \% Tap Weight in the Emulsion}

The largest value of $\%$ tap weight in the emulsion is that of heat S1828, at $49.5 \%$. This is a supported value with several points of different blows above the $40 \%$ mark and at only twice the overall average calculated, compared to that of the highest ART being nearly four times its overall average calculated.

When \% tap weight trends are compared to lance height profiles as reported previously by Millman et al. ${ }^{24)}$ it can be seen that changes in lance height have an effect on the $\%$ tap weight in emulsion. Regardless of direction, a change in lance height appears to increase the value, whereas long periods of stagnated lance height tend to cause a trend back towards a minimum of around $10 \%$ (most values are above this after the initial 2 minute calculation).

It is difficult to interpret the effects of different levels of metal mass in the emulsion upon refining output directly, as without information on size distribution the effect on surface area and mass transport times are effectively unknown. Further work on IMPHOS data is planned to deliver better understanding in this area. a)

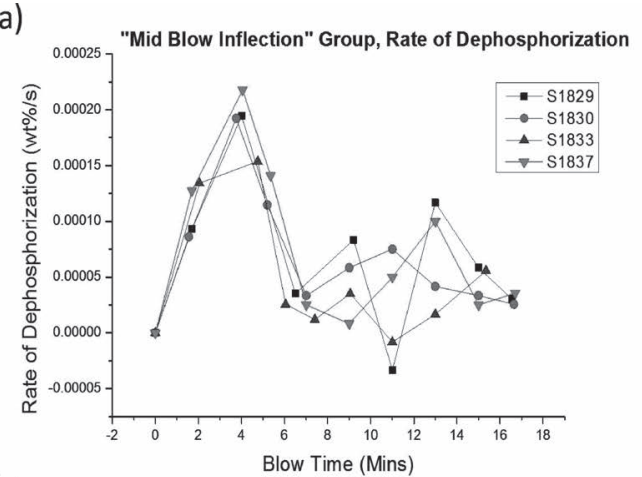

b)

"High Start then Fluctuation" Group, Rate of Dephosphorizat

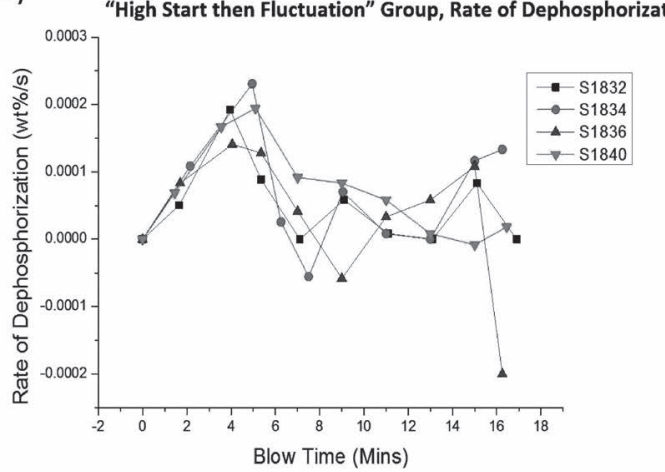

C) "Residual Heats" Group, Rate of Dephosphorization

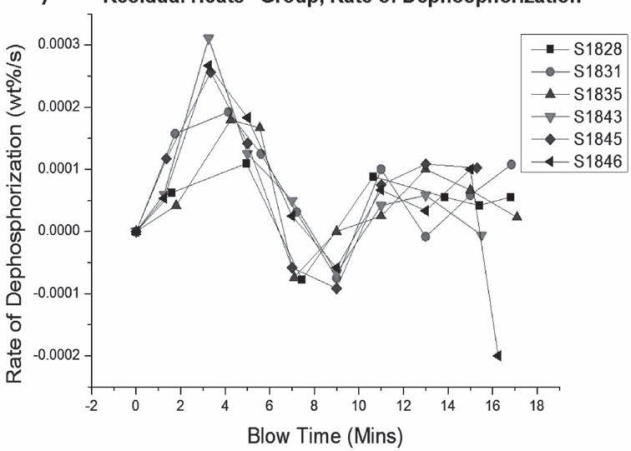

Fig. 8. Rates of dephosphorization from IMPHOS analysis. a) "Mid blow inflection" group, b) "High start then fluctuation" group, c) "Residual heats" group.

\subsection{Metal Circulation Rates}

The metal circulation rates have an apparent vast range. With the highest value being $2120.39 \mathrm{~kg} \mathrm{~s}^{-1}$ from heat S1837 which is hugely out of scale from the majority of values below $150 \mathrm{~kg} \mathrm{~s}^{-1}$. This value is partially due to the calculated ART being the only value computed for the parameter below one second, as a result effectively doubling the $\%$ tap weight in order to calculate metal circulation rate. As there is little agreement in \% tap weight values in end blow, this trend of high MCR towards the end of the blow can be attributed to a reduction in ART. This effect is not seen in early blow where residence times are also 'low' because effects such as significantly lower masses of metal in the emulsion are also playing a role causing the effect to be reduced due to the nature of the model.

This is understandable due to reduction in metal droplet bloating from decarburization; the smaller higher-density metal packages would be able to penetrate through the slag medium with greater ease. Also when events such as slag layer collapse are considered, along with the sampling technique where only samples submerged in the slag layer 
are considered, it is unsurprising these circulation rates are so high when a consistent ejection of material from the bulk bath is coupled with a reduction in emulsion zone volume. It is also possible that due to the reduced effective emulsion zone, the assumption of $100 \%$ decarburization in the emulsion begins to break down, and the process is governed more strongly by bulk bath/slag interactions and hot zone refining.

With the exclusion of the high end values, there is still a general trend for MCR to increase as the blow time increases. This is a very slight increase and may be accounted for through measurement of emulsion viscosity reduction due to temperate increase (reducing slag viscosity), or higher gas fraction contribution to the overall emulsion composition. Evidence for the latter is shown by the sudden peak in decarburization shown in S1832 at 10 minutes into the blow, followed shortly by a brief increase in metal circulation rate by almost $90 \mathrm{~kg} \mathrm{~s}^{-1}$.

\subsection{Evaluation of Assumptions}

The main observation that lead to the diversion from the previously reported model by Millman et al. ${ }^{25)}$ was sample collection time being shown to have no overall effect on sample amount collected. As a result the method reported here was formulated. It is believed by the author that the actual sampling time does not simply correlate linearly with pot opening time, neither is it instantaneous; sampling is most likely to be variable, dependent upon height within the converter. As such a sample from level 4 would be more likely to be instantaneous as it is submerged in a denser, lower gas fraction medium. Whereas a sample at level 7 (which would be in a possibly more foam like medium) would have a continued filling for as long as the pot was open.

The assumption of constant population is at this stage believed to be fair. Metal circulation rates are not far from steady state, apart from an accountable rise through the main blow. Also an evaluation in the change in amount of material collected in consecutive samples shows mostly small variation.

Fair sampling of the converter is difficult to define. With the likelihood of interactions such as streams of metal possibly hitting a sample pot when open (which would be unrepresentative of the bulk emulsion phase), material over counting is a possibility. The other side to this assumption is that the environment is similar through a $2 \mathrm{D}$ horizontal sectioning of the converter. This environment will be significantly different close to the converter wall as opposed to at the oxygen lance in the centre. Recent work by Sabah and Brooks, ${ }^{26,27)}$ using a scaled-down cold model of water and air, has given significant support to this case. The authors intend to evaluate these effects in further work.

Finally there is the assumption of $100 \%$ decarburization occurring within the emulsion zone. This is known not to be accurate but offers an initial estimation to construct this work. From the droplet size analysis carried out through $\mathrm{XCT}$ of the samples from heat S1840, coupled with the use of a decarburization rate per unit area and an average droplet size, it is possible to do a simple carbon mass balance to evaluate this assumption. The solid density of $7.874 \mathrm{~g} \mathrm{~cm}^{-3}$, and a decarburization rate of $7.5 \times 10^{-7} \mathrm{~mol} \mathrm{~s}^{-1}$ a lower bound taken from Molloseau \& Fruehan's work ${ }^{23)}$ are used (an over estimation due to the closest available data being that for a $1 \mathrm{~g}$ droplet).

$\mathrm{S} 1840$ offers a mass of $554.82 \mathrm{~kg}$ metal in the emulsion and mean average droplet diameter of $324 \mu \mathrm{m}$ at the respective time. The calculated number of droplets is $3.957 \times 10^{6}$. With an average droplet size ratio used the mass of $\mathrm{CO}_{2}$ generated per second for one droplet to be $4.627 \times 10^{-6} \mathrm{~g}$ $\mathrm{s}^{-1}$, and an overall $\mathrm{CO}_{2}$ generation for the emulsion of 0.131 $\mathrm{kg} \mathrm{s}^{-1}$. At this point in time off-gas analysis detected 0.202 $\mathrm{kg} \mathrm{s}^{-1}$ of $\mathrm{CO}_{2}$. This gives a $64.6 \%$ possible contribution of $\mathrm{CO}_{2}$ evolution to the droplets within the emulsion phase. A previous report of a similar estimation is made by Cicutti et al. ${ }^{28)}$ where the value range $20-50 \%$ is given for emulsion contribution to refining. From an initial glance this shows the estimation to be reasonable but not of high accuracy.

There are several factors to consider which lead to the calculated value being below what is expected in the true process. Firstly the decarburization rate implemented in the calculation was the most representative in terms of droplet size, this does not take into account the higher iron oxide levels in the slag at the time of calculation in the converter. Secondly the reported decarburization rate is from a static laboratory test where a quiescent gas halo is able to form and diffusion across this halo is likely rate limiting, this is unlikely to be the case in the industrial setting of converter decarburization when mass flow of material in the emulsion phase will disrupt a significant gas boundary forming, meaning ion mass transfer in the slag is more likely rate limiting. Given recent findings reported by Assis ${ }^{29}$ and Spooner, ${ }^{30}$ where droplets are seen to spontaneously emulsify and the extreme increase in surface area this invokes, high values of emulsification contribution are possible. This would allow significantly higher decarburization rates, as such the above calculation does not take into account the morphology of detected droplets; spherical droplets are assumed.

The initial IMPHOS report grouped the heats into five dephosphorization profiles. No known reason behind the varied performance of the initial trials or the varied performances seen in industrial practice can be deduced from traditional methods of defining heat characteristics for example: lance height profiles, temperature measurements, input chemistries and slag phase formation. As such the behaviour has begun to be treated as chaotic. The new findings from this report offer new BOF characteristics to be compared with known refining performance measurements allowing for direct explanation of previously unjustified variances, such as peak times in dephosphorisation linking with peak points of average residence times.

The authors intend to carry out further work in order to offer further validation and potential correction terms into the model. Including: sampling time CFD modelling, scale up of sample contents dependant on location and converter zone contributions to the decarburization profiles. It is key to emphasise that without these more intricate additions to the model, there is still strong agreement with the previously reported findings in this area.

\subsection{Consideration of Original IMPHOS Conclusion}

The directly relevant conclusions from IMPHOS follow along with discussion on the insights currently presented findings offer: 
1. "Consistent slag foaming only beings around two thirds of the way into the blow."

a. Both percentage tap weight values and residence time values show less irregularity between heats in the last third of the blow. As slag formation, and foaming begin in a more sustained and predictable way (as well as a "deeper" slag layer), behaviour such as convection, droplet bloating/ trajectory and interaction with the furnace walls are likely to offer greater influence over metal droplet conditions than the fluctuating and erratic interaction of the high speed oxygen lance with the bulk metal bath, causing different splashing conditions.

b. The initial third of the blow shows the largest diversity in macroscopic dynamics, this is also the period of the blow when lance height, and temperature change most dramatically in a typical blow.

2. "Phosphorus removal takes place from the start of the blow." (addressed with conclusion 3)

3. "Dephosphorization depends on changes in oxidation state of the slag and is driven by metal droplet-slag reactions and NOT bulk bath-slag reactions."

a. This is supported with the high levels of residence time often seen in early blow, as is the characteristic of both the "mid blow inflection" and "high start then fluctuation" groupings.

b. High residence times- longer periods of sustained metal droplet/slag interactions allow for greater dephosphorization rates through reaction of dissolved $\mathrm{P}$ in the steel with $\mathrm{FeO}$ in the slag phase.

4. "Five alternative phosphorus removal profiles have been identified."

a. The first profiles presented in the original IMPHOS trials are at best qualitative. The performance of these heats and characterisation into the five profiles are not explained through traditional heat characteristics. The observations made showing residence time and \% tap weight profiles linking to rates of dephosphorization in this work being to provide explanation as to why variable phosphorus refining performances are seen. Heats S1835 and S1836 show high levels of metal still in the emulsion phase at the end of the blow, thus for example the reduction of available oxygen for final carbon removal due to lance extraction or a final increase in temperature due to increased insulation from a stagnant slag foam, the larger amount of metal in the emulsion phase creates a susceptible condition for phosphorus reversion back into the liquid metal.

\section{Conclusion}

The $\%$ tap weight in the emulsion, average residence time of metal in the emulsion and metal circulation rate within the emulsion have all been calculated for a 6 tonne BOS converter. The residence times reported show correlation with previously reported data from other authors, as well as reasonable correlation with carbon and phosphorus profiles.
$\%$ tap weights are high and show up to nearly $50 \%$ of the overall metal may be suspended in the emulsion at a point in time. Metal circulation rates are shown to be rising in the order of a few $\mathrm{kg} \mathrm{s}^{-1}$ throughout the blow; until end blow where these can increase dramatically, most likely due to slag collapse and the density of droplets being higher due to reduced decarburization. These calculations come from the first comprehensive set of data where a functional converter has been sampled in-situ at several time points during the same blow.

Assumption accuracy has been post analysed giving evidence for model validity in the current state. The novel use of XCT to interrogate droplet population within the emulsion zone, has also been conducted showing a 3D analysis of none sectioned droplets to provide evidence to the amount of decarburization possible in the gas/slag/metal emulsion.

\section{Acknowledgments}

The authors wish to thank Tata Steel for providing the funding and IMPHOS data to conduct this study.

\section{REFERENCES}

1) M. Millman, A. Kapilashrami, M. Bramming and D. Malmberg: Imphos, Improving Phosphorus Refining, European Commision, Reseach Fund for Coal and Steel, Brussels, (2011).

2) M. S. Millman, A. Overbosch, A. Kapilashrami, D. Malmberg and M. Brämming: Trans. Indian Inst. Met., 66 (2013), 525.

$3)$ R. Hüsken, R. Fechner and J. Cappel: Iron Steel Technol., 8 (2011), 46.

4) C. L. Briant and S. K. Banerji: Treatise Science Technology, Academic Press, Cambridge, Massachusetts, (1983), 21.

5) W. M. Guo, Z. C. Wang, Y. De Li, N. Xu and J. B. Shi: Metallogr. Microstruct. Anal., 2 (2013), 249.

6) N. Sano and P. V. Riboud: Advanced Physical Chemistry for Process Metallurgy, Academic Press, Cambridge, MA, (1997).

7) M. A. Tayeb, R. Fruehan and S. Sridhar: Proc. Int. Symp. on Liquid Metal Processing and Casting, John Wiley \& Sons, Hoboken, New Jersey, (2013), 353.

8) M. A. Tayeb, R. Fruehan and S. Sridhar: AISTech, AIST, Warrendale, PA, (2014), 1.

9) C. P. Manning and R. J. Fruehan: Metall. Mater. Trans. B, 44 (2012), 37.

10) P. Wei, M. Sano, M. Hirasawa and K. Mori: ISIJ Int. 33 (1993), 479.

11) W. Pan, M. Sano, M. Hirasawa and K. Mori: ISIJ Int., 31 (1991), 358.

12) H. W. Meyer: J. Iron Steel Inst., 207 (1969), 781.

13) A. M. and G. S. R. F. Block: Arch Eisenhuttenwes., 44 (1973), 357.

14) R. C. Urquhart and W. G. Davenport: Can. Metall. Q., 12 (1973), 507.

15) W. Resch: Ph.D. Thesis, Technical University Clausthal, (1976).

16) Y. V. I. Baptizmanskii, V. B. Okhoskii, K. S. Provirin, G. A. Shcherdrin: Steel USSR, 7 (1977), 329.

17) S. C. Koria and K. W. Lange: Metall. Trans. B, 15 (1984), 109.

18) S. C. Koria and K. W. Lange: Ironmaking Steelmaking, 13 (1986), 236.

19) D. J. Price: Process Eng. Pyrometallurgy, IMM, London, (1974), 8.

20) J. Kumar, A. Attridge, P. K. C. Wood and M. A. Williams: Meas. Sci. Technol., 22 (2011), 15.

21) N. Otsu: Automatica, 11 (1975), 23.

22) G. Brooks, Y. Pan and K. Coley: Metall. Mater. Trans. B, 36 (2005), 525

23) C. Molloseau and R. Fruehan: Metall. Mater. Trans. B, 33 (2002), 335 .

24) M. S. Millman, A. Overbosch, A. Kapilashrami, D. Malmberg and M. Brämming: Ironmaking Steelmaking, 38 (2011), 499.

25) M. S. Millman, A. Overbosch, A. Kapilashrami, D. Malmberg and M. Brämming: Ironmaking Steelmaking, 40 (2013), 460.

26) S. Sabah and G. Brooks: ISIJ Int., 54 (2014), 836.

27) S. Sabah and G. Brooks: Metall. Mater. Trans. B, 46 (2014), 863.

$28)$ R. D. Donayo, L. F. C. Cicutti, M. Valdez, T. Perez, J. Petroni and A. Gomez: 12th IAS Steelmaking Seminar, Instituto Argention de Siderugia, Argentina, (1999).

29) A. N. Assis, J. Warnett, S. Spooner, R. J. Fruehan, M. A. Williams and S. Sridhar: Metall. Mater. Trans. B, 46 (2014), 568.

30) S. Spooner, A. N. Assis, J. M. Warnett, R. J. Fruehan, M. A. Williams and S. Sridhar: Metall. Mater. Trans. B, 47 (2016), 2123. 